\title{
The Effects of Health IT Adoption on Hospital Readmission Reduction: Evidence from U.S. Panel Data
}

\author{
Yongjin Park \\ KAIST College of Busiess \\ yongjin.park@kaist.ac.kr
}

\author{
Youngsok Bang \\ CUHK Business School \\ youngsokbang@cuhk.edu.hk
}

\author{
Juhee Kwon \\ KAIST College of Business \\ kwon.juhee@kaist.ac.kr
}

\begin{abstract}
U.S. government subsidies under the HITECH Act of 2009 have boosted hospitals' IT investments, which are expected to improve the quality of care as well as the effectiveness of healthcare management. Given the rush to adopt health information technology (HIT) throughout the continuum of care across healthcare providers, this study tries to identify the spillover effects of HIT adoption on quality of care. Using 1,965 U.S. hospital data in 232 health referral regions (HRRs), we examine how a hospital's and its neighboring hospitals' HIT adoptions interact with each other and how they impact readmission rates. We find that a hospital's readmission rate is reduced by both its own and neighbors' HIT adoption. Such effects become greater along with the focal hospital's own adoption. We further investigate how spillover effects vary with HRRs, different market structures and hospitals' meaningfuluse status. Our findings offer theoretical and managerial insights for both healthcare researchers and practitioners.
\end{abstract}

\section{Introduction}

Health information technology (HIT) has been expected to help healthcare providers better manage the timeliness and accuracy of patient care by supporting effective clinical decisions and information sharing among patients and their caregivers. Thanks to the Health Information Technology for Economic and Clinical Health (HITECH) Act of 2009, U.S. healthcare providers have been given financial incentives linked to HIT adoption. More than $\$ 35$ billion in incentives has promoted HIT implementation, resulting in $96 \%$ of hospitals having a certified electronic health records program in 2017—a nine-fold increase since 2008 [22].

\footnotetext{
1 A clinical decision support system (CDSS) uses knowledge bases for providing clinical information at the point of care to drive evidence-based treatment (e.g., clinical guidelines and reminders,
}

During the last decade, this dramatically increased HIT adoption has promoted healthcare researchers justify the government initiatives to drive large private and public investments. However, most of the prior studies have focused on the hospital- or physician-level effects of HIT adoption on healthcare quality and costs $[1,2,6]$.

However, unlike other industries, the healthcare sector often shares patient information as patients move across healthcare providers within a hospital referral region (HRR). Thus, a hospital's HIT adoption does not only affect the adopter itself but also its neighboring hospitals. For instance, clinical and patient information from a clinical decision support system $(\mathrm{CDSS})^{1}$ is utilized by physicians in writing referral letters, which inform the medical decisions of referred hospitals in an HRR. Primary care physicians' referrals to special services are often accompanied by information sharing through electronic data interchange (EDI), which expedites communication and collaboration among healthcare providers [17]. Therefore, the HIT adoptions of hospitals in an HRR seem to have spillover effects.

In addition, the patterns of such referrals vary with an HRR's market structure. If a single tertiary hospital dominates a local healthcare market, all primary and secondary care hospitals would not have any choice, whereas they would have multiple options otherwise. Thus, the spillover effect of HIT adoption on quality of care in HRRs having various market structures is an important empirical question.

Although HIT adoption can result in the spillover effects in terms of better healthcare outcomes, some studies demonstrated that most of the benefits from HIT adoption are not caused by the simple implementation. The assimilation gap between the implementation and the actual usage of HIT [12] would explain the effects of HITs. Thus, we further consider the meaningful use of adopted HIT in our empirical models. 
With regard to the above discussions, our primary research questions are: (1) How does a hospital's HIT adoption affect its quality of care? (2) Do the spillover effects of HIT adoption exist among hospitals in an HRR? (3) How do the spillover effects vary with different market structures? (4) How is the meaningful use of HITs related to the effects on healthcare quality?

In order to answer the questions, the large-scale hospital panel datasets were obtained from multiple sources, including the Healthcare Information and Management Systems Society (HIMSS) Analytics database and the Centers for Medicare and Medicaid Services (CMS) website ${ }^{2}$. Our sample includes healthcare data involving 1,965 hospitals across 232 HRRs from 2010 to 2015, such as adopted HITs and detailed healthcare quality.

Our findings provide theoretical and practical implications by identifying the interdependence of HIT adoption among hospitals in an HRR. The contribution of the study lies in providing policy insights on effective healthcare policies across complex healthcare market structures.

\section{Research background}

The impact of HIT adoption has recently drawn attention from the community of Information Systems [1]. Several efforts have been devoted to examining its impacts on diverse dimensions, including productivity $[7,11,13,16,20,24]$, medical errors $[2,8,15,18]$, insurance premiums [19], and healthcare quality [4, 6, 14, 23]. For example, Menon et al. [20] show that two healthcare information systems-clinical information systems and administrative information systems - have different impacts on patient days and medical labor productivity. Based on the results, they argue that aggregating HIT investment may not lead to a correct conclusion due to these different effects. Aron et al. [2] provide empirical evidence that automating the core error prevention functions between hospitals reduced their interpretative and procedural medical errors. Menon and Kohli [19] analyze hospital panel data in Washington State and show that past HIT expenditures, measured by depreciation expenses, are negatively associated with malpractice insurance premiums and are positively associated with healthcare quality. Bhargava and Mishra [7] focus on physician productivity after adopting electronic health records systems. They found that such an adoption could bring about immediate drops in physician productivity; however, these

\footnotetext{
2 The Centers for Medicare \& Medicaid Services (CMS) is a federal agency as part of the U.S. Department of Health and Human Services. CMS serves Medicare and Medicaid beneficiaries and also oversees
}

productivity drops can be recouped in the long run if the systems are a good fit with physicians' task requirements.

A few recent studies $[3,5,21]$ have focused on the inter-organizational effects of HIT adoption, as well. Most notably, Atasoy et al. [3] find that adopting electronic health records reduces the cost of neighboring hospitals by creating significant regional spillover effects. Ayabakan et al. [5] show that medical test duplication can be reduced with inter-organizational information-sharing technologies.

While prior literature has studied the effects of HIT from diverse perspectives, no study has considered the spillover effects of HIT on quality of care in HRRs having different market competitions. Thus, we aim to address these gaps in the literature by empirically examining how the interaction between the HIT adoptions of a focal hospital and its neighboring hospitals in an HRR influence quality of care. We focus not only on the main effect of HIT adoption but also on its spillover effects within the HRR. We also compare the spillover effects across HRRs with different market concentrations and discuss the role of meaningful use in generating the effects.

Furthermore, we examine the technology interdependence between two HIT applications, particularly the role of EDI in generating the spillover effects of an adopted CDSS. Considering the spillover effects of HIT adoption in an HRR, EDI is one of the most important factors to facilitate the network effects of other HITs, while CDSS is a HIT application related to avoidance of errors and right clinical decisions resulting in enhanced health outcomes. Thus, to answer our research questions, we focus on investigating the spillover effects of a hospital's EDI and CDSS adoption on its readmission rate, which is a widely accepted measure of healthcare quality.

Our study provides evidence that the adoptions of both EDI and CDSS are positively associated with a subsequent reduction in readmission rates for heart failure across hospitals in the U.S. We also find that the average adoption rate of a hospital's neighbors is significantly associated with a subsequent reduction in the hospital's readmission rate. The effect is greater when both a hospital and its neighbors in an HRR have adopted the same technology. Lastly, the meaningful use of HITs, which is captured by the Stage 2 certificate, plays a role in explaining the HIT effects.

The rest of the paper is organized as follows. We first describe our data and empirical model; then, we show the main analysis results. Subsequently, we

many federal healthcare programs, including those that involve HIT such as the meaningful use incentive program for electronic health records (EHR). 
conduct an analysis across subsamples with different market concentrations. Next, we examine whether EDI adoption supports the spillover effects of CDSS adoption in an HRR. We also conduct an HRR-level analysis to demonstrate the relationship between the average adoption rate of EDI and CDSS, as well as the hospital readmission rate of HRRs. Lastly, we examine how the meaningful use of HITs is related to the effects. We conclude our paper with theoretical contributions and future research directions.

\section{Empirical analysis}

\subsection{Data description}

We obtained data from multiple sources. Hospitals' IT infrastructure, HIT adoption, operating expenses and other organizational characteristics were collected from the HIMSS Analytics database. Readmission rates and meaningful-use status were collected from the CMS website. We matched the observations of the same hospital from different sources based on Medicare provider codes, hospital names, addresses and zip codes.

Our interests reside in Medicare hospitals whose information has been publicly announced. Further, to examine possible spillover effects within an HRR, we chose HRRs that have at least three Medicare hospitals. The final longitudinal sample includes 232 HRRs and 1,965 hospitals that have reported their annual status from 2010 to 2015.

As noted earlier, in order to identify the spillover effects of HIT on quality of care, this study focuses on examining the effects of EDI and CDSS on subsequent readmission rates for heart failure patients.

A hospital readmission is defined as "an unplanned admission to an acute care hospital within 30 days of discharge from the same or another acute care hospital" [10]. Readmission rates were collected from CMS as a three-year rolling average at the hospital level for heart failure. Readmission indicates a poor quality of healthcare service during the initial hospitalization, because a discharged patient's health has worsened and financial costs increase. Since the U.S. government financially penalizes hospitals whose readmission rates are above a projected rate, hospitals have striven to lower their readmission rates. While a readmission rate has been accepted as a core quality measure, heart failure has been the leading diagnosis of hospital readmission, with a median risk-standardized readmission rate of $23 \%$, from 2009 to 2012 [9].

Table 1 provides the definition and summary statistics of the main variables used in our analysis. Figure 1 illustrates the HRRs across states, which are used in our analysis. A larger and darker circle represents that more hospitals exist in the HRR.

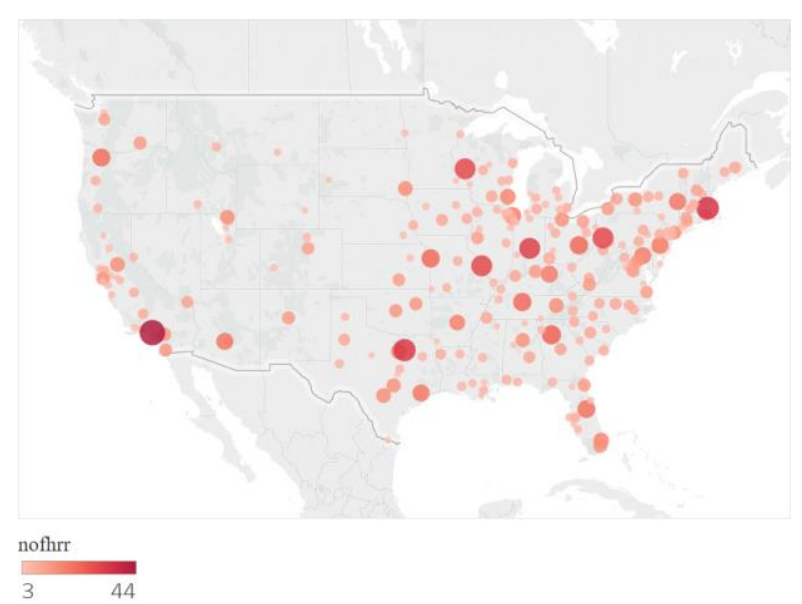

Figure 1. Hospitals in HRRs

Table 1. Definition of key variables and descriptive statistics

\begin{tabular}{|l|l|c|c|c|c|c|}
\hline \multicolumn{1}{|c|}{ Variables } & \multicolumn{1}{|c|}{ Definition } & $\mathrm{N}$ & Mean & SD & Min & Max \\
\hline rhfscore & $\begin{array}{l}\text { Readmission rate of heart failure within 30 days } \\
\text { following a discharge }\end{array}$ & 9,541 & 0.228 & 0.020 & 0.158 & 0.321 \\
\hline EDI & $\begin{array}{l}\text { One year lagged adoption status of electronic } \\
\text { data interchange (1=implemented, 0=0therwise) }\end{array}$ & 9,541 & 0.930 & 0.255 & 0 & 1 \\
\hline CDSS & $\begin{array}{l}\text { One year lagged adoption ratio of the clinical } \\
\text { decision support system }\end{array}$ & 9,541 & 0.691 & 0.342 & 0 & 1 \\
\hline $\ln ($ nofcda $)$ & Number of computerized document applications & 9,541 & 1.351 & 0.124 & 0 & 1.386 \\
\hline $\ln ($ nofbeds $)$ & Number of beds & 9,541 & 5.111 & 0.958 & 2.565 & 7.533 \\
\hline $\ln ($ opexp $)$ & Operating expense (USD) & 9,541 & 18.690 & 1.093 & 14.927 & 22.975 \\
\hline $\ln ($ nofhrr $)$ & Number of hospitals in the referral regions & 9,541 & 2.477 & 0.627 & 1.386 & 3.807 \\
\hline HHI & Herfindahl-Hirschman Index of referral regions & 9,541 & 0.218 & 0.148 & 0.032 & 0.859 \\
\hline
\end{tabular}

Note: A clinical decision support system includes drug content and interactions, clinical guidelines and pathways for physicians, as well as clinical guidelines and pathways for nurses; computerized document applications include computerized practitioner order entries, clinical data repositories, electronic medical records, and electronic medication administration records. 


\subsection{Empirical approach}

We employ a fixed effects model that controls for time-invariant hospital-level covariates. We examine how a hospital's (and its neighboring hospitals') HIT adoptions affect the hospital's readmission rate (Eq. 1). We also consider the network effect of HIT adoption by incorporating the interaction term between the HIT adoption of the focal hospital and the adoption rate of its neighbors in an HRR into the main effect model (Eq. 2). Our model specifications are:

$$
\begin{aligned}
r h f_{i, t}= & \beta_{0}+\beta_{1} H I T_{i, t-1}+\beta_{2} H I T_{r-i, t-1}+\gamma X_{i, t} \\
& +\mu_{i}+\varepsilon_{i, t} \\
r h f_{i, t}= & \beta_{0}+\beta_{1} H I T_{i, t-1}+\beta_{2} H I T_{r-i, t-1} \\
& +\beta_{3} H I T_{i, t-1} \times H I T_{r-i, t-1}+\gamma X_{i, t}+\mu_{i}+\varepsilon_{i, t} \text { (Eq. 2) }
\end{aligned}
$$

where $r h f_{i, t}$ is the readmission rate of the heart failure cases of hospital $i$ at time $t, H I T_{i, t-1}$ is the adoption state of the HIT (EDI or CDSS) of hospital $i$ at time $t-1$, $H I T_{r-i, t-1}$ is the average adoption rate of the other hospitals in the same HRR $r$, except for the focal hospital $i$ at time $t-1, X_{i, t}$ is a vector of the control variables, $\mu_{i}$ is the hospital-specific fixed effects, and $\varepsilon_{i, t}$ is the disturbance term.

Our control variables are time-varying hospital-level covariates, including the number of computerized document applications, number of beds, operating expenses, and an HRR's market concentration. The number of computerized healthcare systems are included to control for effects due to the hospitals' IT infrastructure. The number of beds and the operating expenses are included to control for the effect of organizational size. The number of hospitals and the Herfindahl-Hirschman Index (HHI) are included to control HRR's market structure. Lastly, our fixed effects term controls for effects due to all time-invariant hospital-specific factors.

\subsection{Results}

Table 2 illustrates our results. Models (1) and (3) indicate that the coefficients of $H I T_{i, t-1}$ are negative and significant for both EDI and CDSS (-0.006 and 0.005 at $p$-value $<0.01$, respectively), demonstrating that the adoption status of those HITs is negatively associated with the subsequent readmission rates of heart failure patients. This result provides evidence of the positive effects of EDI and CDSS adoption on quality of care. $H I T_{r-i, t-1}$ also has a negative and significant coefficient for both EDI and CDSS (-0.058 and -0.065 at $p$-value $<0.01$, respectively), implying that the average adoption rate of a hospital's neighboring hospitals in an HRR is negatively associated with the subsequent readmission rate of the focal hospital. The results demonstrate the spillover effects of HITs within an HRR.

In Models (2) and (4), we investigate the interaction effect between the adoption status of the focal hospital and the average adoption rate of the other hospitals. The coefficients of the interaction term of $H I T_{i, t-1}$ and $H I T_{r-i, t-1}$ are negative and significant for both EDI and CDSS (-0.016 at $p$-value $<0.01$ and -0.012 at $p$-value $<0.05$, respectively). These suggest that the spillover effects of HIT are stronger when both the focal hospital and its neighbors have adopted the same type of HIT. Among the control variables, the number of computerized document applications (nofcda $a_{i, t}$ ), the number of beds (nofbed $d_{i, t}$ ), the operating expense $\left(\operatorname{opexp}_{i, t}\right)$, and the Herfindahl-Hirschman Index $\left(H H I_{i, t}\right)$ are negatively associated with the readmission rate. The number of hospitals in the referral region $\left(\right.$ nofhrr $\left._{i, t}\right)$ is omitted from the analysis due to high multi-collinearity with other covariates (Mean VIF=14.22 in Model (6)).

\section{Additional analysis}

\subsection{Subsample analysis}

With respect to our discussion in the introduction, a hospital's choice for referrals requiring communication and information sharing between practitioners should be related to an HRR's market structure. We employ the Herfindahl-Hirschman Index (HHI), which is a commonly accepted measure for market concentration in considering the spillover effects across HRRs having diverse market structures. According to the U.S. Department of Justice and the Federal Trade Commission, an index below 0.15 indicates that the market is unconcentrated, and an index between 0.15 and 0.25 indicates that the market is moderately concentrated. An index above 0.25 indicates that the market is highly concentrated. We employ this cutoff to classify the HRRs each year. Our dataset includes 855 , 507 , and 603 hospitals in the low, moderate, and high market concentration groups, respectively.

We replicate our panel analysis for these three subsamples. Tables 3, 4, and 5 show the results from HHRs with an HHI of less than 0.15 (Panel A), between 0.15 and 0.25 (Panel B), and more than 0.25 (Panel C), respectively. 
Table 2. Estimation results

\begin{tabular}{|c|c|c|c|c|c|c|}
\hline Variables & $(1)$ & $(2)$ & (3) & $(4)$ & $(5)$ & (6) \\
\hline$E D I_{i, t-1}$ & $\begin{array}{c}-0.006^{\star \star \star} \\
(0.001)\end{array}$ & $\begin{array}{c}0.007 \\
(0.005)\end{array}$ & & & $\begin{array}{c}0.002 \\
(0.005)\end{array}$ & $\begin{array}{c}0.001 \\
(0.005)\end{array}$ \\
\hline$E D I_{r-i, t-1}$ & $\begin{array}{c}-0.058^{* * *} \\
(0.002)\end{array}$ & $\begin{array}{c}-0.044^{* k+} \\
(0.006)\end{array}$ & & & $\begin{array}{c}-0.024^{*+*} \\
(0.006)\end{array}$ & $\begin{array}{c}-0.028^{*+*} \\
(0.006)\end{array}$ \\
\hline$E D I_{i, t-1} \times E D I_{r-i, t-1}$ & & $\begin{array}{c}-0.016^{* * \star} \\
(0.006)\end{array}$ & & & $\begin{array}{c}-0.005 \\
(0.006) \\
\end{array}$ & $\begin{array}{c}0.000 \\
(0.008) \\
\end{array}$ \\
\hline$C D S S_{i, t-1}$ & & & $\begin{array}{c}-0.005^{\star \star \star *} \\
(0.002)\end{array}$ & $\begin{array}{c}0.002 \\
(0.004) \\
\end{array}$ & $\begin{array}{c}0.006^{*} \\
(0.004)\end{array}$ & $\begin{array}{c}0.003 \\
(0.003) \\
\end{array}$ \\
\hline$C D S S_{r-i, t-1}$ & & & $\begin{array}{c}-0.065^{\star \star \star \star} \\
(0.003)\end{array}$ & $\begin{array}{l}-0.056^{* * *} \\
(0.004)\end{array}$ & $\begin{array}{c}-0.039^{* * *} \\
(0.005)\end{array}$ & $\begin{array}{c}-0.030^{* * *} \\
(0.006)\end{array}$ \\
\hline $\operatorname{CDSS}_{i, t-1} \times C D S S_{r-i, t-1}$ & & & & $\begin{array}{l}-0.012^{* *} \\
(0.005)\end{array}$ & $\begin{array}{l}-0.010^{*} \\
(0.005)\end{array}$ & $\begin{array}{l}-0.011^{* *} \\
(0.005)\end{array}$ \\
\hline$C D S S_{i, t-1} \times E D I_{i, t-1} \times E D I_{r-i, t-1}$ & & & & & $\begin{array}{l}-0.005^{*} \\
(0.003)\end{array}$ & \\
\hline$C D S S_{r-i, t-1} \times E D I_{i, t-1} \times E D I_{r-i, t-1}$ & & & & & & $\begin{array}{l}-0.010^{*} \\
(0.005)\end{array}$ \\
\hline $\ln \left(\operatorname{nof} c d a_{i, t}\right)$ & $\begin{array}{c}-0.022^{* * *} \\
(0.002)\end{array}$ & $\begin{array}{c}-0.022^{* * *} \\
(0.002)\end{array}$ & $\begin{array}{c}-0.020^{\star * \star} \\
(0.002)\end{array}$ & $\begin{array}{c}-0.020^{* * *} \\
(0.002)\end{array}$ & $\begin{array}{c}-0.018^{\star \star \star \star} \\
(0.002)\end{array}$ & $\begin{array}{l}-0.018^{* * *} \\
(0.002)\end{array}$ \\
\hline $\ln \left(\right.$ nofbed $\left._{i, t}\right)$ & $\begin{array}{c}-0.003 \\
(0.002) \\
\end{array}$ & $\begin{array}{c}-0.003 \\
(0.002) \\
\end{array}$ & $\begin{array}{l}-0.004^{* *} \\
(0.002)\end{array}$ & $\begin{array}{l}-0.004^{* *} \\
(0.002)\end{array}$ & $\begin{array}{l}-0.004^{*} \\
(0.002)\end{array}$ & $\begin{array}{l}-0.004^{*} \\
(0.002)\end{array}$ \\
\hline $\ln \left(\right.$ opexp $\left._{i, t}\right)$ & $\begin{array}{c}-0.004^{* * *} \\
(0.001)\end{array}$ & $\begin{array}{c}-0.004^{* * *} \\
(0.001)\end{array}$ & $\begin{array}{c}-0.004^{* * *} \\
(0.001)\end{array}$ & $\begin{array}{l}-0.004^{* * *} \\
(0.001)\end{array}$ & $\begin{array}{l}-0.003^{* * *} \\
(0.001)\end{array}$ & $\begin{array}{l}-0.003^{* *} \\
(0.001)\end{array}$ \\
\hline$H H I_{i, t}$ & $\begin{array}{c}-0.042^{* \star \star x} \\
(0.004)\end{array}$ & $\begin{array}{c}-0.042^{* * *} \\
(0.004)\end{array}$ & $\begin{array}{c}-0.036^{* * *} \\
(0.004)\end{array}$ & $\begin{array}{c}-0.036^{* * *} \\
(0.004)\end{array}$ & $\begin{array}{c}-0.032^{* * *} \\
(0.004)\end{array}$ & $\begin{array}{l}-0.032^{* * *} \\
(0.004)\end{array}$ \\
\hline Constant & $\begin{array}{l}0.408^{* * \star} \\
(0.021)\end{array}$ & $\begin{array}{l}0.397^{* * t} \\
(0.022)\end{array}$ & $\begin{array}{l}0.414^{* * t} \\
(0.021)\end{array}$ & $\begin{array}{l}0.410^{* * *} \\
(0.021)\end{array}$ & $\begin{array}{l}0.391^{* * *} \\
(0.020)\end{array}$ & $\begin{array}{l}0.389^{* * *} \\
(0.020)\end{array}$ \\
\hline Fixed-effects & Yes & Yes & Yes & Yes & Yes & Yes \\
\hline$R^{2}$ & 0.244 & 0.245 & 0.275 & 0.276 & 0.307 & 0.307 \\
\hline Observations & 9,541 & 9,541 & 9,541 & 9,541 & 9,541 & 9,541 \\
\hline Number of hospitals & 1,965 & 1,965 & 1,965 & 1,965 & 1,965 & 1,965 \\
\hline
\end{tabular}

Note: Robust standard errors are in parentheses; ${ }^{* * *} p<0.01,{ }^{* *} p<0.05,{ }^{*} p<0.1$.

Table 3. Estimation results for HRRs with an HHI below 0.15 (Panel A)

\begin{tabular}{|c|c|c|c|c|c|c|}
\hline Variables & $(1)$ & $(2)$ & (3) & $(4)$ & $(5)$ & $(6)$ \\
\hline$E D I_{i, t-1}$ & $\begin{array}{c}-0.007^{\star \star \star} \\
(0.002)\end{array}$ & $\begin{array}{c}0.009 \\
(0.011)\end{array}$ & & & $\begin{array}{c}0.004 \\
(0.012)\end{array}$ & $\begin{array}{c}-0.009 \\
(0.014)\end{array}$ \\
\hline$E D I_{r-i, t-1}$ & $\begin{array}{c}-0.093^{\text {k*k }} \\
(0.004)\end{array}$ & $\begin{array}{c}-0.076^{\text {**x }} \\
(0.013)\end{array}$ & & & $\begin{array}{c}-0.017 \\
(0.014)\end{array}$ & $\begin{array}{l}-0.030^{*} \\
(0.016)\end{array}$ \\
\hline$E D I_{i, t-1} \times E D I_{r-i, t-1}$ & & $\begin{array}{l}-0.019 \\
(0.013)\end{array}$ & & & $\begin{array}{c}-0.012 \\
(0.014)\end{array}$ & $\begin{array}{c}0.022 \\
(0.020)\end{array}$ \\
\hline$C D S S_{i, t-1}$ & & & $\begin{array}{l}-0.005^{\star *} \\
(0.002)\end{array}$ & $\begin{array}{c}0.006 \\
(0.006)\end{array}$ & $\begin{array}{c}0.008 \\
(0.006) \\
\end{array}$ & $\begin{array}{c}0.004 \\
(0.007) \\
\end{array}$ \\
\hline$C D S S_{r-i, t-1}$ & & & $\begin{array}{c}-0.099^{* \star *} \\
(0.005)\end{array}$ & $\begin{array}{c}-0.086^{\star \star \star} \\
(0.008)\end{array}$ & $\begin{array}{c}-0.062^{* \star \star} \\
(0.010)\end{array}$ & $\begin{array}{c}-0.050^{* * *} \\
(0.011)\end{array}$ \\
\hline $\operatorname{CDSS}_{i, t-1} \times C D S S_{r-i, t-1}$ & & & & $\begin{array}{l}-0.018^{\star *} \\
(0.009)\end{array}$ & $\begin{array}{l}-0.025^{\star \star} \\
(0.010)\end{array}$ & $\begin{array}{c}-0.014 \\
(0.010)\end{array}$ \\
\hline$C D S S_{i, t-1} \times E D I_{i, t-1} \times E D I_{r-i, t-1}$ & & & & & $\begin{array}{c}0.005 \\
(0.006)\end{array}$ & \\
\hline$C D S S_{r-i, t-1} \times E D I_{i, t-1} \times E D I_{r-i, t-1}$ & & & & & & $\begin{array}{l}-0.025^{\star \star} \\
(0.012)\end{array}$ \\
\hline Constants & $\begin{array}{l}0.365^{\star * \star} \\
(0.035)\end{array}$ & $\begin{array}{l}0.350^{\star * *} \\
(0.038)\end{array}$ & $\begin{array}{l}0.341^{* \star \star} \\
(0.033)\end{array}$ & $\begin{array}{l}0.334^{\star * \star} \\
(0.033)\end{array}$ & $\begin{array}{l}0.327^{* * \star} \\
(0.035)\end{array}$ & $\begin{array}{l}0.332^{* * *} \\
(0.036)\end{array}$ \\
\hline Controls & Yes & Yes & Yes & Yes & Yes & Yes \\
\hline Fixed-effects & Yes & Yes & Yes & Yes & Yes & Yes \\
\hline$R^{2}$ & 0.303 & 0.304 & 0.357 & 0.358 & 0.364 & 0.365 \\
\hline Observations & 4,168 & 4,168 & 4,168 & 4,168 & 4,168 & 4,168 \\
\hline Number of hospitals & 855 & 855 & 855 & 855 & 855 & 855 \\
\hline
\end{tabular}

Note: Robust standard errors are in parentheses. ${ }^{* * *} p<0.01,{ }^{* *} p<0.05,{ }^{*} p<0.1$. The results of the control variables are not shown for expositional brevity. 
Table 4. Estimation results for HRRs with an HHI between 0.15 and 0.25 (Panel B)

\begin{tabular}{|c|c|c|c|c|c|c|}
\hline Variables & $(1)$ & $(2)$ & (3) & (4) & $(5)$ & (6) \\
\hline$E D I_{i, t-1}$ & $\begin{array}{l}-0.004^{\star} \\
(0.002)\end{array}$ & $\begin{array}{c}0.016 \\
(0.010)\end{array}$ & & & $\begin{array}{c}0.015 \\
(0.011)\end{array}$ & $\begin{array}{c}0.019 \\
(0.012)\end{array}$ \\
\hline$E D I_{r-i, t-1}$ & $\begin{array}{l}-0.061^{\star \star \star} \\
(0.004)\end{array}$ & $\begin{array}{c}-0.040^{\star \star \star} \\
(0.011)\end{array}$ & & & $\begin{array}{l}-0.017 \\
(0.012)\end{array}$ & $\begin{array}{l}-0.015 \\
(0.013)\end{array}$ \\
\hline$E D I_{i, t-1} \times E D I_{r-i, t-1}$ & & $\begin{array}{l}-0.024^{\star \star} \\
(0.011)\end{array}$ & & & $\begin{array}{l}-0.015 \\
(0.013) \\
\end{array}$ & $\begin{array}{l}-0.030^{*} \\
(0.017)\end{array}$ \\
\hline$C D S S_{i, t-1}$ & & & $\begin{array}{l}-0.005^{\star} \\
(0.003)\end{array}$ & $\begin{array}{l}-0.006 \\
(0.008)\end{array}$ & $\begin{array}{c}0.003 \\
(0.009) \\
\end{array}$ & $\begin{array}{c}-0.003 \\
(0.008)\end{array}$ \\
\hline $\operatorname{CDSS}_{r-i, t-1}$ & & & $\begin{array}{c}-0.066^{\star \star \star} \\
(0.005)\end{array}$ & $\begin{array}{c}-0.068^{* \star *} \\
(0.010)\end{array}$ & $\begin{array}{l}-0.051^{* * *} \\
(0.011)\end{array}$ & $\begin{array}{c}-0.052^{\star \star \star} \\
(0.013)\end{array}$ \\
\hline$C D S S_{i, t-1} \times C D S S_{r-i, t-1}$ & & & & $\begin{array}{c}0.002 \\
(0.012) \\
\end{array}$ & $\begin{array}{c}0.005 \\
(0.013) \\
\end{array}$ & $\begin{array}{l}-0.002 \\
(0.013)\end{array}$ \\
\hline$C D S S_{i, t-1} \times E D I_{i, t-1} \times E D I_{r-i, t-1}$ & & & & & $\begin{array}{l}-0.013^{\star *} \\
(0.006)\end{array}$ & \\
\hline$C D S S_{r-i, t-1} \times E D I_{i, t-1} \times E D I_{r-i, t-1}$ & & & & & & $\begin{array}{c}0.007 \\
(0.011)\end{array}$ \\
\hline Constants & $\begin{array}{l}0.427^{\star * \star} \\
(0.046)\end{array}$ & $\begin{array}{l}0.411^{\star * \star} \\
(0.047)\end{array}$ & $\begin{array}{l}0.403^{* * \star} \\
(0.045)\end{array}$ & $\begin{array}{l}0.403^{* \star *} \\
(0.045)\end{array}$ & $\begin{array}{c}0.379^{\star \star *} \\
(0.044)\end{array}$ & $\begin{array}{c}0.381^{* * *} \\
(0.044)\end{array}$ \\
\hline Controls & Yes & Yes & Yes & Yes & Yes & Yes \\
\hline Fixed-effects & Yes & Yes & Yes & Yes & Yes & Yes \\
\hline$R^{2}$ & 0.221 & 0.223 & 0.250 & 0.250 & 0.291 & 0.289 \\
\hline Observations & 2,481 & 2,481 & 2,481 & 2,481 & 2,481 & 2,481 \\
\hline Number of hospitals & 507 & 507 & 507 & 507 & 507 & 507 \\
\hline
\end{tabular}

Note: Robust standard errors are in parentheses. ${ }^{* * *} p<0.01,{ }^{* *} p<0.05,{ }^{*} p<0.1$. The results of the control variables are not shown for expositional brevity.

Table 5. Estimation results for HRRs with an HHI above 0.25 (Panel C)

\begin{tabular}{|c|c|c|c|c|c|c|}
\hline Variables & (1) & $(2)$ & (3) & $(4)$ & $(5)$ & (6) \\
\hline$E D I_{i, t-1}$ & $\begin{array}{l}-0.005^{\star \star} \\
(0.002)\end{array}$ & $\begin{array}{c}-0.000 \\
(0.006)\end{array}$ & & & $\begin{array}{c}-0.004 \\
(0.006) \\
\end{array}$ & $\begin{array}{c}-0.004 \\
(0.006)\end{array}$ \\
\hline$E D I_{r-i, t-1}$ & $\begin{array}{c}-0.040^{* * \star} \\
(0.002)\end{array}$ & $\begin{array}{c}-0.035^{* \star *} \\
(0.007)\end{array}$ & & & $\begin{array}{c}-0.025^{\star * \star} \\
(0.007)\end{array}$ & $\begin{array}{l}-0.029^{* * *} \\
(0.007)\end{array}$ \\
\hline$E D I_{i, t-1} \times E D I_{r-i, t-1}$ & & $\begin{array}{c}-0.005 \\
(0.008)\end{array}$ & & & $\begin{array}{c}0.007 \\
(0.008)\end{array}$ & $\begin{array}{c}0.007 \\
(0.009)\end{array}$ \\
\hline$C D S S_{i, t-1}$ & & & $\begin{array}{l}-0.004^{*} \\
(0.002)\end{array}$ & $\begin{array}{c}-0.000 \\
(0.004) \\
\end{array}$ & $\begin{array}{c}0.007 \\
(0.005) \\
\end{array}$ & $\begin{array}{c}-0.001 \\
(0.004) \\
\end{array}$ \\
\hline$C D S S_{r-i, t-1}$ & & & $\begin{array}{c}-0.044^{\star \star \star} \\
(0.003)\end{array}$ & $\begin{array}{l}-0.040^{* \star *} \\
(0.005)\end{array}$ & $\begin{array}{l}-0.030^{\star \star \star} \\
(0.006)\end{array}$ & $\begin{array}{l}-0.020^{* * \star} \\
(0.007)\end{array}$ \\
\hline $\operatorname{CDSS}_{i, t-1} \times C D S S_{r-i, t-1}$ & & & & $\begin{array}{c}-0.006 \\
(0.007) \\
\end{array}$ & $\begin{array}{c}0.001 \\
(0.007) \\
\end{array}$ & $\begin{array}{c}-0.003 \\
(0.006) \\
\end{array}$ \\
\hline$C D S S_{i, t-1} \times E D I_{i, t-1} \times E D I_{r-i, t-1}$ & & & & & $\begin{array}{c}-0.013^{\star \star \star *} \\
(0.005)\end{array}$ & \\
\hline$C D S S_{r-i, t-1} \times E D I_{i, t-1} \times E D I_{r-i, t-1}$ & & & & & & $\begin{array}{c}-0.010 \\
(0.006)\end{array}$ \\
\hline Constants & $\begin{array}{c}0.413^{\star \star *} \\
(0.031)\end{array}$ & $\begin{array}{c}0.410^{\star * *} \\
(0.031)\end{array}$ & $\begin{array}{c}0.446^{\star * *} \\
(0.030)\end{array}$ & $\begin{array}{c}0.445^{\star * \star} \\
(0.030)\end{array}$ & $\begin{array}{l}0.425^{\star \star \star} \\
(0.029)\end{array}$ & $\begin{array}{l}0.420^{* * *} \\
(0.029)\end{array}$ \\
\hline Controls & Yes & Yes & Yes & Yes & Yes & Yes \\
\hline Fixed-effects & Yes & Yes & Yes & Yes & Yes & Yes \\
\hline$R^{2}$ & 0.245 & 0.245 & 0.255 & 0.255 & 0.301 & 0.299 \\
\hline Observations & 2,892 & 2,892 & 2,892 & 2,892 & 2,892 & 2,892 \\
\hline Number of hospitals & 603 & 603 & 603 & 603 & 603 & 603 \\
\hline
\end{tabular}


The coefficients for $H I T_{i, t-1}$ are negative and significant in all subsamples. The coefficients for $H I T_{r-i, t-1}$ are also negative and significant for both EDI and CDSS in all subsamples (-0.093, -0.061, and -0.040 for EDI and $-0.099,-0.066$, and -0.044 for CDSS, for Panels A, B, and C, respectively). To compare the spillover effects across subsamples, we further estimate our models with the standardized variables. The standardized coefficients of $H I T_{r-i, t-1}$ for Panels A, B, and $\mathrm{C}$ are $-0.605,-0.400$, and -0.264 for EDI and -0.808 , -0.541 , and -0.368 for CDSS, respectively. These results consistently indicate the spillover effects of HIT adoption are negatively proportional to HRRs' HHIs. We test the equality of the coefficients across panels and find that the difference between the standardized coefficients from Panel A and Panel B, and Panel B and Panel $\mathrm{C}$ is statistically significant for both EDI and CDSS (the $t$-values are -5.048 and -3.297 for EDI, and 4.785 and -3.847 for CDSS, respectively). The results imply that spillover effects are greatest for HRRs with a low-concentrated market, followed by HRRs with a moderately and a highly concentrated market. Further, the coefficient estimate of the interaction term is found significant only for CDSS and in low-concentrated markets $(-0.018$ at $p$-value $<0.01$ in Model (4) at Table 3).

The results illustrate that spillover effects depend on HRRs' market structures. Specifically, the effects are prevalent when the healthcare market is very competitive, such that there are many hospital choices for referrals or collaborations. These effects, however, diminish when a few hospitals are dominating in the referral region.

\subsection{The role of EDI in generating the spillover effects of CDSS}

EDI systems have been adopted to support effective communication among hospitals. EDI allows hospitals to exchange electronic clinical documentation such as patient demographics, physician notes, nursing notes, medication lists, and problem lists in a fast and errorless manner. The diagnosis and treatment history, and medication records supported by CDSS at the initial hospital can be safely transmitted to the referred hospital through the system.

To estimate the technology dependency of CDSS on EDI in generating spillover effects, we incorporate a three-way interaction term into our main models (Eq. 3 and Eq. 4):

$$
\begin{aligned}
r h f_{i, t}= & \beta_{0}+\beta_{1} E D I_{i, t-1}+\beta_{2} E D I_{r-i, t-1}+\beta_{3} E D I_{i, t-1} \times \\
& E D I_{r-i, t-1}+\beta_{4} C D S S_{i, t-1}+\beta_{5} C D S S_{r-i, t-1}+ \\
& \beta_{6} C D S S_{i, t-1} \times C D S S_{r-i, t-1}+\beta_{7} E D I_{i, t-1} \times \\
& E D I_{r-i, t-1} \times C D S S_{i, t-1}+\gamma X_{i, t}+\mu_{i}+\varepsilon_{i, t}
\end{aligned}
$$

$r h f_{i, t}=\beta_{0}+\beta_{1} E D I_{i, t-1}+\beta_{2} E D I_{r-i, t-1}+\beta_{3} E D I_{i, t-1} \times$

$E D I_{r-i, t-1}+\beta_{4} \operatorname{CDSS}_{i, t-1}+\beta_{5} \operatorname{CDSS}_{r-i, t-1}+$

$\beta_{6} \operatorname{CDSS}_{i, t-1} \times \operatorname{CDSS}_{r-i, t-1}+\beta_{7} E D I_{i, t-1} \times$

$E D I_{r-i, t-1} \times C D S S_{r-i, t-1}+\gamma X_{i, t}+\mu_{i}+\varepsilon_{i, t}$

(Eq. 4)

Models (5) and (6) of Table 1 contain the analysis results. The negative and significant coefficient of $E D I_{i, t-1} \times E D I_{r-i, t-1} \times C D S S_{i, t-1}$ demonstrates that the main effects of CDSS adoption are greater when both a focal hospital and its neighbors have implemented EDI. The negative and significant coefficient of $E D I_{i, t-1} \times E D I_{r-i, t-1} \times C D S S_{r-i, t-1}$ demonstrates that the spillover effect of CDSS adoption is significant among hospitals in an HRR. These findings further imply that the effects of hospitals' CDSS and EDI adoptions are interdependent for delivering high-quality healthcare service.

\subsection{Network externality: HRR-level analysis}

Considering possible spillover effects, the overall HIT adoption at the HRR level could contribute to the healthcare quality of the region. We conduct an HRRlevel analysis to examine how an HRR's average adoption rates of EDI and CDSS affect its average readmission rate. The model specifications are the same

\begin{tabular}{|c|c|c|c|c|}
\hline Variables & (1) & (2) & (3) & (4) \\
\hline$E D I_{r, t-1}$ & $\begin{array}{c}-0.034^{* \star *} \\
(0.005)\end{array}$ & & $\begin{array}{c}-0.026^{\star \star \star} \\
(0.004)\end{array}$ & $\begin{array}{c}-0.017 \\
(0.013)\end{array}$ \\
\hline$C D S S_{r, t-1}$ & & $\begin{array}{c}-0.032^{\star * \star} \\
(0.004)\end{array}$ & $\begin{array}{c}-0.027^{\star \star \star} \\
(0.004)\end{array}$ & $\begin{array}{l}-0.012 \\
(0.019) \\
\end{array}$ \\
\hline $\begin{array}{l}E D I_{r, t-1} \\
\times C D S S_{r, t-1}\end{array}$ & & & & $\begin{array}{l}-0.016 \\
(0.020)\end{array}$ \\
\hline Constants & $\begin{array}{l}0.748^{* * \star} \\
(0.070)\end{array}$ & $\begin{array}{l}0.767^{\star \star \star} \\
(0.067)\end{array}$ & $\begin{array}{l}0.734^{* * *} \\
(0.066)\end{array}$ & $\begin{array}{l}0.724^{* * *} \\
(0.066)\end{array}$ \\
\hline Controls & Yes & Yes & Yes & Yes \\
\hline Fixed-effects & Yes & Yes & Yes & Yes \\
\hline$R^{2}$ & 0.449 & 0.463 & 0.487 & 0.487 \\
\hline Observations & 1,150 & 1,150 & 1,150 & 1,150 \\
\hline $\begin{array}{l}\text { Number of } \\
\text { HRRs }\end{array}$ & 232 & 232 & 232 & 232 \\
\hline
\end{tabular}
as our main models, except that all of the variables are HRR-level.

Table 6. HRR-level estimation results

Note: $E D I_{r, t-1}\left(C D S S_{r, t-1}\right)$ is the average adoption rate of EDI (CDSS) of the HRR $r$ at $t-1$. The dependent variable is the average readmission rate of heart failure in the HRR. The results of the control variables are not shown for expositional brevity. 
Table 6 contains the results. The average adoption rates of EDI $(-0.026$ at $p$-value $<0.01)$ and CDSS (0.027 at $p$-value $<0.01)$ in an HRR are associated with a decrease in the average readmission rate of the HRR, which illustrates the negative effects. However, their interaction does not have any effect at the HRR level.

\subsection{Meaningful use}

In terms of HIT adoption, an assimilation gap between simple HIT implementation and actual usage could exist in a hospital [12], and gap ranges are possibly diverse across hospitals. Such gaps normally result from a lack of knowledge in leveraging various types of HIT and misalignment between HIT and internal clinical workflows. Thus, we further integrate a hospital's actual usage, which is measured as a hospital's meaningful-use attestation, into our models.

This analysis can identify how the effect of HIT adoption varies with a hospital's actual usage. Actual usage was measured by whether a hospital attested to the meaningful-use Stage 2, which was initiated in 2014 and expanded the meaningful-use Stage 1 criteria (i.e., improving data capture and sharing) to advanced care processes with decision support. The purposes of the meaningful-use Stage 2 beyond Stage 1 are well aligned with the adoption of CDSS and EDI. While Stage 1 does not pay much attention to data exchange and the use of CDSS, Stage 2 requires all medical documents to be sent electronically to other hospitals for at least 50 percent of referral cases and concerns the meaningful use of CDSS functionalities.

Thus, we further test whether meaningful use, which is measured by the receipt of the Stage 2 certificate, makes any difference on the spillover effects of HIT adoption. We apply our panel models, Eq. 1 and Eq. 2, to hospitals that are certified as Stage 2 and hospitals that are not certified, separately. There are 1,525 hospitals in Stage 2 and 440 hospitals in Stage 1 or below in 2015 .

Table 7 shows the estimation results. With respect to Stage 2 hospitals, the estimates for $H I T_{i, t-1}$ and $H I T_{r-i, t-1}$ are negative and significant in Models (1) and (3), and the estimates for their interaction terms are also negative and significant for both EDI and CDSS in Models (2) and (4).

However, in Stage 1 hospitals, the effects of HIT adoption (especially, CDSS) become insignificant in Model (6) (8), suggesting that hospitals having relatively low-level actual usage cannot fully utilize adopted CDSS for a better quality of care. Further, the interaction terms of $H I T_{i, t-1}$ and $H I T_{r-i, t-1}$ have insignificant coefficients for both EDI and CDSS (Models (6) and (8)), implying that meaningful HIT usage drives the spillover effects in an HRR.

\section{Conclusion}

This study investigates the effects of CDSS and EDI on the hospital readmission rates for heart failure patients. Using the large-scale hospital panel datasets from multiple sources, we find evidence that a hospital's HIT adoption is associated with a subsequent reduction in its readmission rate. We also reveal the spillover effects of HIT adoption within an HRR. These spillover effects become stronger for an HRR with less concentrated healthcare markets - competitive healthcare markets. Furthermore, our results indicate that a focal hospital's EDI adoption along with its neighboring hospitals is critical in fostering the spillover effects of CDSS adoption in the HRR.

Our results highlight the importance of governmentdriven HIT investments in the U.S. The spillover effects become greater for hospitals that have adopted HIT, along with a higher HIT adoption level within the HRR. The negative impact of HIT adoption on a hospital's readmission rate can be greater with the adoption of the other hospitals in the HRR.

Such spillover effects vary with the market concentrations of regional healthcare markets. The spillover effects of both EDI and CDSS are strongest for HRRs with an unconcentrated healthcare market, followed by HRRs with a moderately concentrated healthcare market. The spillover effects are weakest for HRRs with a highly concentrated healthcare market. This finding suggests that policies for effective HIT adoption should consider various regional market structures. Therefore, government interventions aiming at maximizing the spillover effects of HIT adoption need to be tailored, based on types of healthcare market structures.

The spillover effect of CDSS adoption becomes greater when a focal hospital adopts EDI and the average EDI adoption rate of neighboring hospitals in its HRR is higher. EDI adoption moderates the spillover effects of CDSS adoption. This indicates the technology interdependence among HITs in enhancing healthcare quality. 
Table 7. Estimation results of hospitals by meaningful use

\begin{tabular}{|c|c|c|c|c|c|c|c|c|}
\hline & \multicolumn{4}{|c|}{ Hospitals in Stage 2} & \multicolumn{4}{|c|}{ Hospitals in Stage 1 or Below } \\
\hline Variables & (1) & (2) & (3) & (4) & $(5)$ & $(6)$ & (7) & (8) \\
\hline$E D I_{i, t-1}$ & $\begin{array}{c}-0.007^{\star \star \star} \\
(0.002)\end{array}$ & $\begin{array}{c}0.006 \\
(0.006)\end{array}$ & & & $\begin{array}{l}-0.004^{\star} \\
(0.002)\end{array}$ & $\begin{array}{c}0.010 \\
(0.010)\end{array}$ & & \\
\hline$E D I_{r-i, t-1}$ & $\begin{array}{c}-0.058^{\star * \star} \\
(0.003)\end{array}$ & $\begin{array}{c}-0.043^{* * *} \\
(0.006)\end{array}$ & & & $\begin{array}{c}-0.059^{* \star *} \\
(0.004)\end{array}$ & $\begin{array}{c}-0.044^{* * *} \\
(0.012)\end{array}$ & & \\
\hline$E D I_{i, t-1} \times E D I_{r-i, t-1}$ & & $\begin{array}{l}-0.016^{*} \\
(0.007)\end{array}$ & & & & $\begin{array}{c}-0.016 \\
(0.012)\end{array}$ & & \\
\hline$C D S S_{i, t-1}$ & & & $\begin{array}{c}-0.006^{\star \star \star} \\
(0.002)\end{array}$ & $\begin{array}{c}0.006 \\
(0.004)\end{array}$ & & & $\begin{array}{c}-0.004 \\
(0.003)\end{array}$ & $\begin{array}{l}-0.010 \\
(0.007)\end{array}$ \\
\hline$C D S S_{r-i, t-1}$ & & & $\begin{array}{c}-0.066^{* \star *} \\
(0.003)\end{array}$ & $\begin{array}{c}-0.053^{* * *} \\
(0.005)\end{array}$ & & & $\begin{array}{c}-0.060^{* * \star} \\
(0.007)\end{array}$ & $\begin{array}{c}-0.066^{* *} \\
(0.008)\end{array}$ \\
\hline $\operatorname{CDSS}_{i, t-1} \times \operatorname{CDSS}_{r-i, t-1}$ & & & & $\begin{array}{c}-0.019^{\star \star \star} \\
(0.006)\end{array}$ & & & & $\begin{array}{c}0.011 \\
(0.011)\end{array}$ \\
\hline Constants & $\begin{array}{l}0.429^{* \star *} \\
(0.025)\end{array}$ & $\begin{array}{l}0.418^{\star \star \star} \\
(0.025)\end{array}$ & $\begin{array}{l}0.431^{\star \star \star} \\
(0.023)\end{array}$ & $\begin{array}{l}0.426^{\star \star \star} \\
(0.023)\end{array}$ & $\begin{array}{l}0.331^{* \star *} \\
(0.042)\end{array}$ & $\begin{array}{l}0.317^{\star \star \star} \\
(0.042)\end{array}$ & $\begin{array}{l}0.346^{* \star *} \\
(0.042)\end{array}$ & $\begin{array}{l}0.348^{\star *} \\
(0.042)\end{array}$ \\
\hline Controls & Yes & Yes & Yes & Yes & Yes & Yes & Yes & Yes \\
\hline Fixed-effects & Yes & Yes & Yes & Yes & Yes & Yes & Yes & Yes \\
\hline$R^{2}$ & 0.235 & 0.236 & 0.274 & 0.276 & 0.290 & 0.291 & 0.283 & 0.284 \\
\hline Observations & 7,464 & 7,464 & 7,464 & 7,464 & 2,077 & 2,077 & 2,077 & 2,077 \\
\hline Number of hospitals & 1,525 & 1,525 & 1,525 & 1,525 & 440 & 440 & 440 & 440 \\
\hline
\end{tabular}

Note: Robust standard errors are in parentheses. ${ }^{* * *} p<0.01,{ }^{* *} p<0.05,{ }^{*} p<0.1$. The results of the control variables are not shown for expositional brevity

Our study contributes to the growing body of literature on the impacts of HITs. While most prior empirical studies focus on the hospital or physicianlevel effects of HIT adoption based on a small sample, we use nationwide large panels to examine not only the hospital-level effects of the adoption but also possible spillover effects at an HRR level. A few recent studies have paid attention to the spillover effects of HIT adoptions; however, their focus is on the cost side $[3,5]$. To the best of our knowledge, this study is one of the first studies to provide empirical evidence of the spillover effects of HIT adoption on healthcare quality considering market concentrations and actual usage beyond simple HIT implementation. The subsample analysis across various market concentrations provides the market conditions where spillover effects can prevail. The analysis on the three-way interaction of EDI adoption, the EDI adoption rate in the HRR, and CDSS adoption highlights the importance of infrastructure for effective communication among hospitals in terms of fostering the spillover effects of standalone technology. We further found that the spillover effects of HIT adoption increase along with higher actual HIT usage.

While we focus on the effects of two types of HITs - CDSS and EDI, the effects of other HITs can be explored as well in the next step. If an analysis of other technologies shows different results, such that no spillover effect is found, it would be interesting to investigate which technological characteristics of HITs drive such differential results. We can also replicate the analysis for other major causes of hospital readmission, such as pneumonia or acute myocardial infarction, in our future research.

\section{References}

[1] Agarwal, R., G.G. Gao, C. DesRoches, and A.K. Jha, "The digital transformation of healthcare: Current status and the road ahead", Information Systems Research 21(4), 2010, pp. 796-809.

[2] Aron, R., S. Dutta, R. Janakiraman, and P. a Pathak, "The Impact of Automation of Systems on Medical Errors : Evidence from Field Research", Information Systems Research 22(3), 2011, pp. 429-446.

[3] Atasoy, H., P.-Y. Chen, and K.K. Ganju, "The Spillover Effects of Health IT Investments on Regional Health Care Costs", Management Science(Forthcoming), 2018, pp. 1-20. [4] Ayabakan, S., I. Bardhan, and E. Zheng, "What Drives Readmission? A New Perspective from Hidden Markov Model Analysis", Proceedings of the 37th International Conference on Information Systems (ICIS), (2016), 1-19. [5] Ayabakan, S., I. Bardhan, Z. (Eric) Zheng, and K. Kirksey, "the Impact of Health Information Sharing on Duplicate Testing", MIS Quartely 41(4), 2017, pp. 10831103.

[6] Bavafa, H., L.M. Hitt, and C. Terwiesch, "The Impact of E-Visits on Visit Frequencies and Patient Health: Evidence from Primary Care", Management Science(Forthcoming), 2018, pp. 1-20.

[7] Bhargava, H.K., and A. Mishra, "Electronic Medical Records and Physician Productivity: Evidence from Panel Data Analysis", Management Science 60(10), 2014, pp. 2543-2562.

[8] Burton-Jones, A., and O. Volkoff, "How can we develop contexualized theories of effective use? A demostration in 
the context of community-care electronic health records", Information Systems Research 28(3), 2017, pp. 468-489. [9] CMS, Medicare Hospital Quality Chartbook: Performance Report on Outcome Measures, Centers for Medicare and Medicaid Services, 2013.

[10] CMS, 2016 Measure Information about the 30-day AllCause Hospital Readmission Measure, Calculated for the 2018 Value-Based Payment Modifier Program, Centers for Medicare and Medicaid Services, 2016.

[11] Devaraj, S., and R. Kohli, "Information technology payoff in the health-care industry: A longitudinal study", Journal of Management Information Systems 16(4), 2000, pp. 41-67.

[12] Fichman, R.G., and C.F. Kemerer, "The Illusory Diffusion of Innovation: An Examination of Assimilation Gaps", Information Systems Research 10(3), 1999, pp. 255 275.

[13] Goh, J.M., G.G. Gao, R. Agarwal, and J.M. Goh, "Evolving Work Routines : Adaptive Routinization of Information Technology in Healthcare", Information Systems Research 22(3), 2011, pp. 565-585.

[14] Kramer, T., A. Tillinghast, and R. Marge, "ROI for an Electronic Medical Record", Behavioral Health Management 19(1), 1999, pp. 28-31.

[15] Li, X., and J. Qin, “Anonymizing and Sharing Medical Text Records”, Information Systems Research 28(2), 2017, pp. 332-352.

[16] Lu, S.F., H. Rui, and A. Seidmann, "Does Technology Substitute for Nurses? Staffing Decisions in Nursing Homes", Management Science 64(4), 2018, pp. 1842-1859. [17] Luft, H.S., D.W. Garnick, D.H. Mark, et al., "Does quality influence choice of hospital?", Journal of the
American Medical Association 263(21), 1990, pp. 28992906.

[18] Mekhjian, H.S., R.R. Kumar, L. Kuehn, et al., "Immediate benefits realized following implementation of physician order entry at an academic medical center", Journal of the American Medical Informatics Association 9(5), 2002, pp. 529-539.

[19] Menon, N., and Kohli, "Blunting Damocles' Sword : A Longitudinal Model of Healthcare IT Impact on Malpractice Insurance Premium and Quality of Patient Care", Information Systems Research 24(4), 2013, pp. 918-932.

[20] Menon, N.M., U. Yaylacicegi, and A. Cezar, "Differential Effects of the Two Types of Information Systems: A Hospital-Based Study", Journal of Management Information Systems 26(1), 2009, pp. 297-316.

[21] Mishra, A.N., C. Anderson, C.M. Angst, and R. Agarwal, "Electronic Health Records Assimilation and Physician Identity Evolution: An Identity Theory Perspective", Information Systems Research 23, No.3,(September 2017), 2012, pp. 738-760.

[22] Reisman, M., "EHRs: The Challenge of Making Electronic Data Usable and Interoperable", Pharmacy and Therapeutics 42(9), 2017, pp. 572-575.

[23] Venkatesh, V., X. Zhang, and T. a Sykes, "'Doctors Do Too Little Technology ': A Longitudinal Field Study of an Electronic Healthcare System Implementation", Information Systems Research 22(3), 2011, pp. 523-546.

[24] Wang, S.J., B. Middleton, L.A. Prosser, et al., "A costbenefit analysis of electronic medical records in primary care", American Journal of Medicine 114(5), 2003, pp. 397 403. 